\title{
Intraductal papillary mucinous tumours of the pancreas. Clinical and therapeutic issues in 32 patients
}

C Azar, J Van de Stadt, F Rickaert, J Devière, M Delhaye, M Baize, G Klöppel, M Gelin, M Cremer

\begin{abstract}
Background/Aim-The clinical presentation, pancreatographic findings, and outcome of patients with intraductal papillary mucinous tumours have not been reported in a large patient series in the English literature. This study reviewed 32 patients diagnosed between 1980 and 1994, with special attention to these features.

Patients/Method-Data on 24 operated and eight non-operated patients were abstracted from inpatient, outpatient, and procedure records.

Results-Acute pancreatitis was the most common presentation seen in $56 \%$ of patients. Relapses occurred during an average of $\mathbf{4 3}$ months before diagnosis. A patulous papilla was observed in $55 \%$ of the cases. Endoscopic pancreatography showed communicating cysts, a diffusely dilated main pancreatic duct, and amorphous defects in 42,71 , and $97 \%$ respectively. An invasive carcinoma was found in nine of $24(37.5 \%)$ of operated patients: six of the patients $(66 \%)$ died or developed metastases within three years after surgery. No mortality was related to the tumour in absence of invasive carcinoma. Benign recurrence on the remaining pancreas was unusual and occurred late after surgery.

Conclusions-Intraductal papillary mucinous tumours must be considered in the differential diagnosis of relapsing pancreatitis. Despite slow growing, these tumours have an obvious malignant potential and a very poor prognosis when invasive carcinoma has developed. Early recognition and resection are the cornerstones of treatment.

(Gut 1996; 39: 457-464)
\end{abstract}

Keywords: acute pancreatitis, pancreatic cancer, papillomatosis, mucinous tumour.

Hôpital Erasme, Université Libre de Bruxelles, Brussels, Belgium

Institute of Pathology, University of Kiel,

Germany

G Klöppel

Correspondence to

Dr J Van de Stadt,

Department of

Medico-Surgical

Hepato-Gastroenterology,

Erasme Hospital

808 route de Lennik,

B-1070 Brussels, Belgium.

Accepted for publication

18 April 1996

Intraductal pancreatic tumours are They represent a group of neoplasms distinct from usual pancreatic adenocarcinoma by their intraductal growth, clinical and pancreatographic features, and a prognosis commonly reported as favourable. ${ }^{3-5}$

Two main types have been reported: intraductal papillary tumours ${ }^{467}$ and intraductal mucin hypersecreting tumours. ${ }^{58}$ As both are indistinguishable histologically and transition between them occurs, they constitute a single tumour entity to which we will refer as intraductal papillary mucinous tumours (IPMT). ${ }^{3}$

Given their rarity, limited information is available about the clinical features of these tumours, in particular their presentation and longterm patient outcome. The aim of this study is therefore to review our experience with a series of 32 IPMTs with particular emphasis on clinical presentation, endoscopic cholangiopancreatographic findings, and disease course in operated and non-operated patients.

\section{Methods}

\section{Patients}

The endoscopic retrograde cholangiopancreatography (ERCP) and pathology records at Erasme University Hospital between January 1980 and December 1994 were reviewed. We identified 32 patients diagnosed with IPMT.

Twenty four patients were operated on and had a definitive pathological diagnosis. Eight patients diagnosed at pancreatography were not operated on because of high surgical risk or refusal. A positive cytology of intraductal brushings was obtained in six patients in the second group. Diagnostic pancreatographic criteria included: (a) diffuse or focal main pancreatic duct (MPD) dilatation in the absence of proximal stricture with intraductal fixed or amorphous filling defects; (b) single or multiple cysts communicating with the MPD with intracystic defects.

Inpatient and outpatient files and procedure records were reviewed for clinical characteristics. We studied modes of presentation, in particular acute pancreatitis defined by upper abdominal pain persisting for $>24$ hours along with a serum amylase of more than two times normal. The initial aetiological diagnosis of pancreatitis, time lag to correct diagnosis, laboratory data including liver, pancreatic enzymes, tumour marker levels (CEA, CA19-9), pancreatic function studies, and ERCP findings were analysed.
Endoscopic procedures

ERCP was performed using the TJF10, TJF20 or TJF100 duodenoscope (Olympus corporation, Hamburg, Germany). The macroscopic appearance of the papilla was noted. Complete pancreatograms were obtained by contrast injection through a $6 \mathrm{~F}$ catheter after selective deep cannulation of the MPD. 
TABLE I Clinical presentation in intraductal papillary mucinous tumours of the pancreas

\begin{tabular}{lll}
\hline & $\begin{array}{c}\text { Patients } \\
(n=32)\end{array}$ & Percentage \\
\hline Pain & & \\
$\quad$ episode(s) of acute pancreatitis & 18 & 56 \\
$\quad$ indolent presentation & 14 & 44 \\
Anorexia & 16 & 50 \\
Diabetes mellitus & 12 & $37 \cdot 5$ \\
Steatorrhea & 4 & $12 \cdot 5$ \\
Obstructive jaundice & 2 & 6 \\
\hline
\end{tabular}

Non-operated patients underwent biliary and pancreatic sphincterotomies to provide ready MPD access for serial ERCP and intraductal brushing, and favour mucus drainage. The largest cyst diameter and MPD calibre in the head, body, and tail segments were measured. Cytology specimens were collected by intraductal brushing using the Geenen biliary brush (Wilson Cook, Winston Salem) or over the wire double lumen brush (Microvasive, Boston, Mass). Smears from brushings were stained by the Diff quick stain (a modified Giemsa stain). Pancreatic exocrine function studies were performed, as previously described, ${ }^{9}$ on pure pancreatic juice collected through a $6 \mathrm{~F}$ nasopancreatic catheter after intravenous secretin injection (1 U/kg).

\section{Pathology \\ Surgical specimens were thoroughly sampled, fixed in $10 \%$ formaldehyde, and paraffin wax embedded. Deparaffinised sections were stained with haematoxylin and eosin. Tumours were classified in accordance to the new World Health Organisation's classification, taking into account the most severe grade of epithelial dysplasia. This classification includes adenomas with mild dysplasia, borderline tumours with moderate dysplasia, intraductal carcinomas with severe dysplasia or carcinoma in situ changes (all these grades concerning tumours confined to the epithelium), and invasive carcinomas when the tumour features stromal invasion. ${ }^{3}$}

\section{Follow up of patients}

Surgical patients were seen at six and 12 months postoperatively and subsequently at
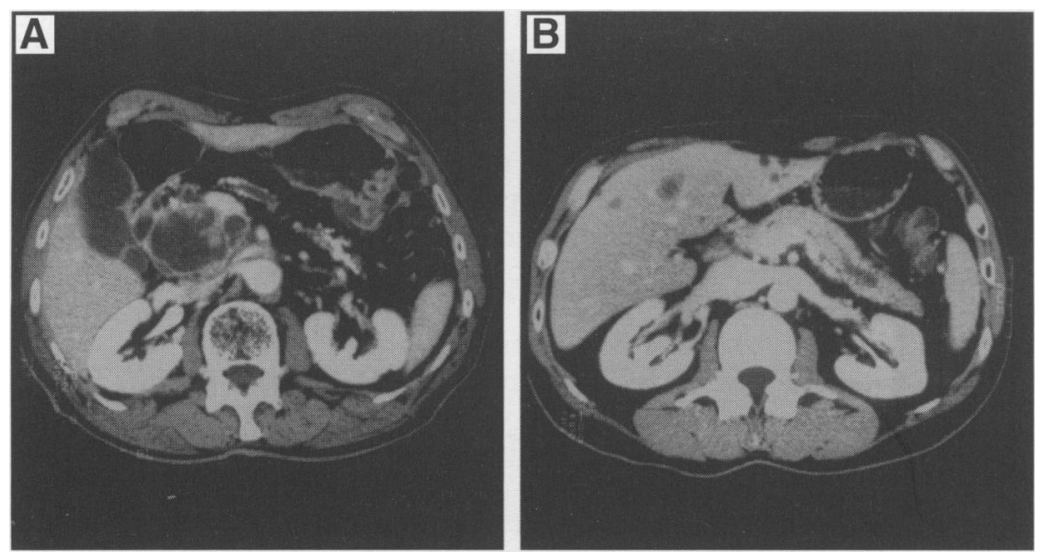

Figure 1: Computed tomography showing (A) a cephalic cyst with septum (B) caudal dilatation of the main pancreatic duct. yearly intervals for five years. Follow up was undertaken by history, physical examination, liver and pancreatic enzymes, tumour marker levels, and abdominal computed tomography. Yearly ERCP was performed in patients who underwent distal pancreatectomy.

Non-operated patients were followed up similarly at yearly intervals or more frequently as clinically indicated with ERCP and intraductal brushings.

Follow up was updated to June 1995 by telephone interview with patients and their physicians.

\section{Results}

\section{Clinical characteristics of patients}

Patients included 24 males and eight females with a mean age of 64 (range 35-82). Eight patients consumed $40-80 \mathrm{~g}$ of alcohol daily for five or more years.

Table I summarises the clinical presentation of the patients. The most common mode of presentation was acute pancreatitis in 18 patients, five of who were alcoholic. Bouts of pancreatitis were mild, or moderate in severity. No systemic or local complications (that is, pancreatic necrosis, pseudocysts) occurred. Episodes of pancreatitis recurred in 17 patients at variable time intervals ranging from weeks to years, during an average period of 43 months (range 2-192), before the diagnosis was considered at pancreatography. Two patients had relapses during 12 and 16 years respectively. A single patient was correctly diagnosed shortly after the first episode. All others were referred with a variety of erroneous aetiological diagnoses: chronic alcoholic pancreatitis in six patients including two who underwent previously a pancreaticojejunostomy, chronic idiopathic pancreatitis in eight, chronic pancreatitis of a dorsal pancreatic duct in one patient, and biliary pancreatitis in two patients who underwent biliary sphincterotomy.

An indolent presentation was noted in 14 patients. Five of them were evaluated because of persistent raised amylase and lipase activities (1.5-3 titres above normal) over one to three years. One of these patients was alcoholic, none had renal failure or evidence of macroamylasaemia. Enzyme activities returned to normal after tumour resection. The diagnostic strategy was focused on the pancreas in seven patients by demonstrating pancreatic imaging abnormalities. Cephalic cysts were seen in six patients (two ultrasound and four on computed tomography (Fig 1). Three patients had a dilated MPD on ultrasound. Imaging of the abdomen was indicated for evaluation of unexplained recent weight loss in three patients, weight loss and steatorrhea in three, and unspecific upper abdominal pain in one. Two patients with cephalic lesions presented with obstructive jaundice related to common bile duct stricture.

Sixteen patients experienced anorexia and weight loss and 12 had diabetes mellitus. Steatorrhea was seen in four patients who had 24 hour faecal fat excretions of 9, 12, 22, and $30 \mathrm{~g}$ respectively. 
TABLE II ERCP in intraductal papillary mucinous tumours of the pancreas

\begin{tabular}{lcc}
\hline & $\begin{array}{c}\text { Patients } \\
(n=31)\end{array}$ & Percentage \\
\hline Patulous papilla & 17 & 55 \\
Diffuse MPD dilatation & 22 & 71 \\
Focal MPD dilatation & 5 & 16 \\
${ }^{\star} \mathrm{H}=2 ; \mathrm{B}-\mathrm{T}=2 ; \ddagger \mathrm{T}=1$ & 13 & 42 \\
Cysts & & \\
$\mathrm{H}=10 ; \mathrm{B}=1, \mathrm{~T}=1$ & 10 & 32 \\
single & 3 & 10 \\
$\quad$ multiple & 30 & 97 \\
Amorphous filling defects & 1 & 3 \\
Wirsungocolonic fistula & 1 & 3 \\
MPD stricture & 4 & 13 \\
CBD obstruction & 3 & 10 \\
$\quad$ distal stricture & 1 & 3 \\
extrinsic compression & & \\
\hline
\end{tabular}

${ }^{\star}$ Head=head, $\nmid \mathrm{B}=$ body,$\ddagger \mathrm{T}=$ tail.

Pancreatic function studies were available on 14 patients. Five had a normal function, nine showed reduced function $(18-68 \%$ of normal values).

CEA and CA 19-9 values were measured in 22 patients. High CA 19-9 values were noted in three patients including two with invasive carcinoma who had values of $330 \mathrm{U} / \mathrm{ml}$ and $30500 \mathrm{U} / \mathrm{ml}$ respectively (normal <33 $\mathrm{U} / \mathrm{ml})$.

\section{ERCP}

Table II sumarises the ERCP findings. Biliary and pancreatic visualisation was obtained in all but one patient who had a percutaneous cholangiogram.

A patulous papilla of Vater distended by translucent mucus was seen in 17 patients (Fig 2), $10(59 \%)$ of whom had a benign lesion. Twenty two patients had diffuse MPD dilatation in the absence of proximal stricture (Fig 3). Focal MPD dilatation was seen in five (Fig 4). In four patients with large cephalic cysts no distal pancreatograms were obtained. The mean maximal MPD diameter was $13 \mathrm{~mm}$ (range 6-20). All dilated ducts showed amorphous filling defects (Fig 5) except one case with a polypoid fixed defect.

Cysts communicating with the ductal system and ranging in diameter from 10 to $70 \mathrm{~mm}$ were noted in 13 patients. Ten had a single cyst

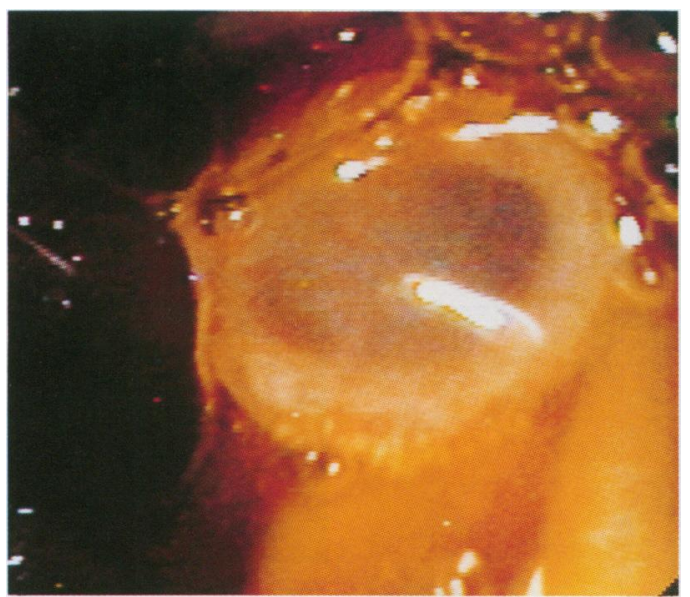

Figure 2: Typical duodenoscopic appearance of a patulous papilla extruding mucus. and three multiple small clustered cysts (Figs 6, $7,8)$. All cysts harboured amorphous defects.

A mid-MPD stricture (Fig 9) and a wirsungotransverse colonic fistula were seen in

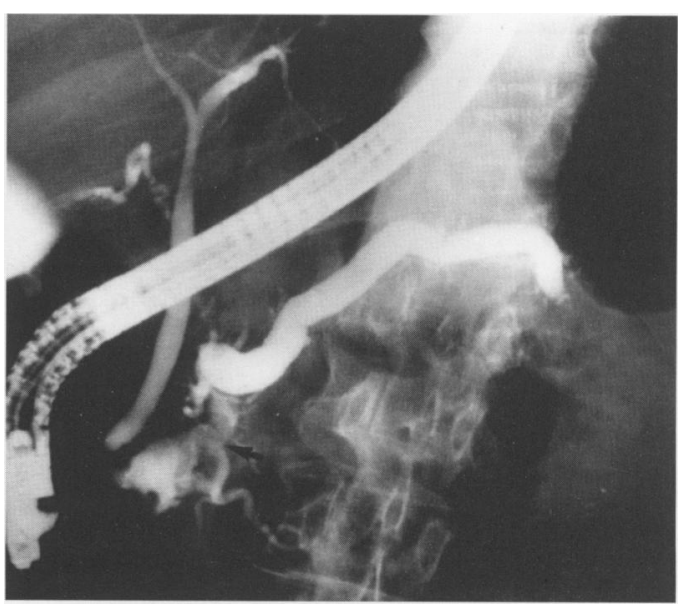

Figure 3: ERCP: diffuse MPD dilatation, note the absence of proximal stricture and amorphous defects (arrow).

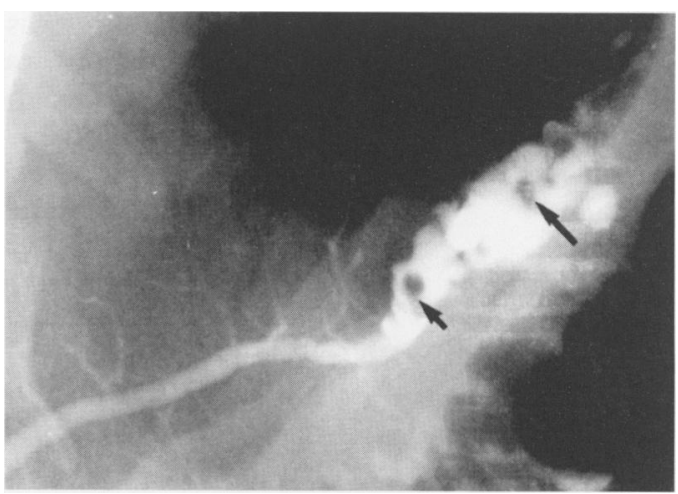

Figure 4: ERCP: MPD dilatation localised to the tail with defects (arrows).

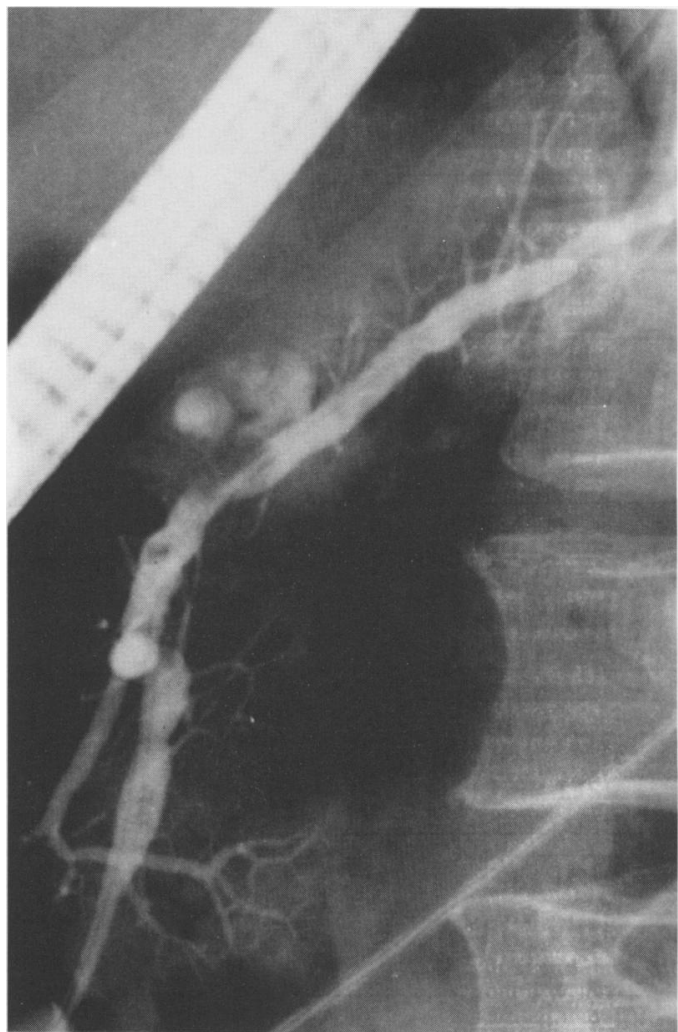

Figure 5: ERCP: intraductal amorphous defects with hazy contours. 


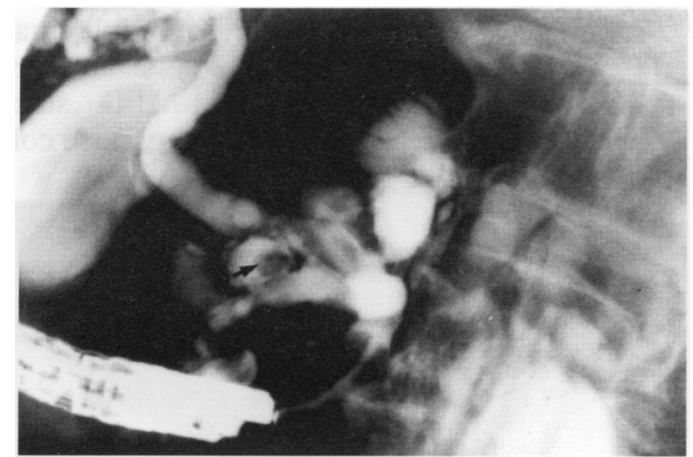

Figure 6: ERCP: a dilated side branch (arrow).

two patients respectively. CBD obstruction was seen in four patients. Three had distal strictures, and one extrinsic compression by a cephalic cystic lesion.

\section{Cytological diagnosis}

Preoperative cytological brushings were successfully obtained in 17 operated patients. Technical failure was encountered in seven. The examination was non-contributive because of poor specimen cellularity or preservation, or both, in 11 patients. A correct diagnosis of benign lesions was established in two patients and a false negative result occurred in two others with invasive carcinoma. Malignancy was detected in two patients after a prolonged preoperative medical follow up (48 and 84 months): both featured progressive diffuse MPD dilatation, obstructive jaundice related to distal $\mathrm{CBD}$ stricture, and raised $\mathrm{CA}$

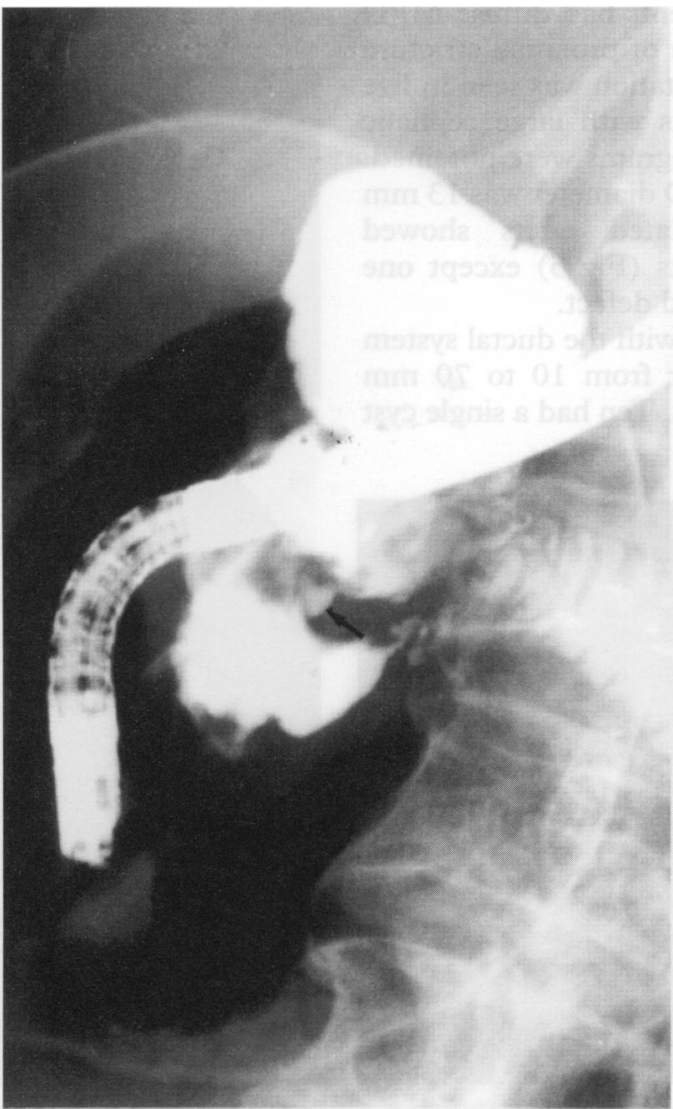

Figure 7: ERCP: large cyst with defects (arrow).

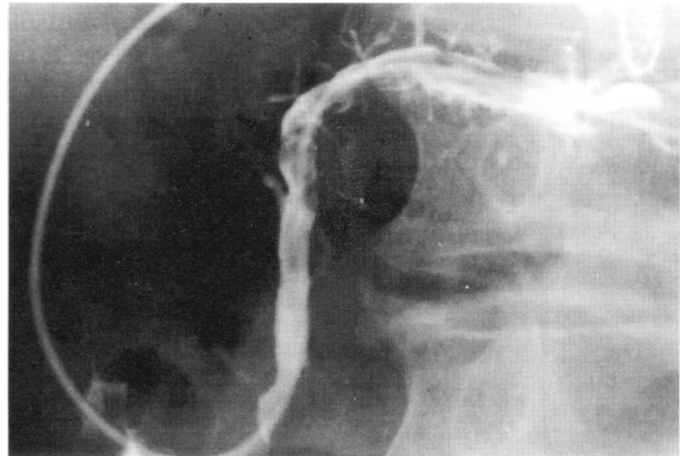

Figure 8: ERCP: multiple clustered cysts with defects (arrow).

19-9 values. Repeated brushings and cytologies were performed: the initial samplings showed benign columnar cells, when the latest examinations showed the development of malignancy, with the presence of a K-ras mutation.

Eight non-operated patients had each an average of two samplings. Cytology was noncontributive in two patients. Benign columnar cells were seen in six.

Surgical treatment and histopathological diagnosis Twenty four patients underwent surgery (Table III). Seventeen were treated by a pancreaticoduodenal resection, for tumours mainly located in the pancreatic head (including two tumours involving diffusely the pancreas). Caudal and segmental pancreatectomies were performed in six cases with tumours developed in the body and the tail,

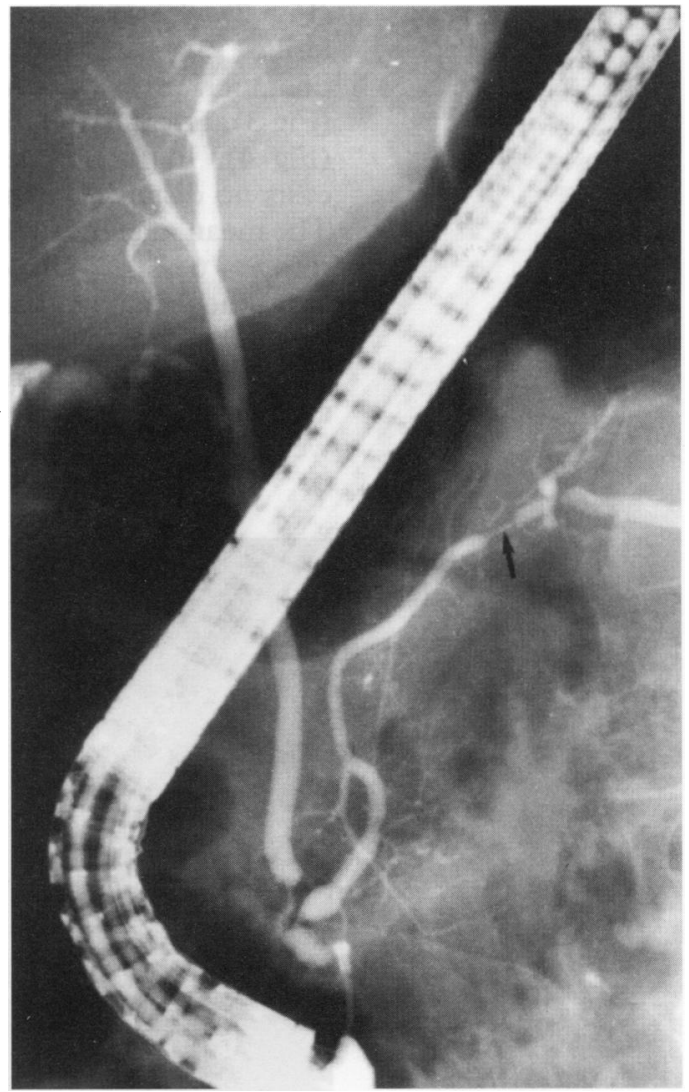

Figure 9: ERCP: MPD stricture: an unusual feature related to circumferential tumour growth without mucin hypersecretion. 
TABLE III Treatment and follow up in 24 surgical patients

\begin{tabular}{|c|c|c|c|c|}
\hline $\begin{array}{l}\text { Specimen } \\
\text { pathology }\end{array}$ & $\begin{array}{l}\text { Site of } \\
\text { neoplasm }\end{array}$ & Surgery & Pancreatic margin & $\begin{array}{l}\text { Follow up } \\
\text { (months) }\end{array}$ \\
\hline \multirow[t]{2}{*}{ Dysplasia ${ }^{\star}$} & $\begin{array}{l}\text { Body } \\
\text { Tail } \\
\text { Tail }\end{array}$ & $\begin{array}{l}\text { SPł } \\
\text { CPS } \\
\text { CP }\end{array}$ & $\begin{array}{l}\text { free } \\
\text { free } \\
\text { mild dysplasia }\end{array}$ & \multirow{3}{*}{$\begin{array}{l}\text { alive } 20 \\
\text { alive } 36 \\
\text { alive } 66 \\
\text { benign recurrence } \\
\text { alive } 84 \\
\text { alive } 74 \\
\text { alive } 97 \\
\text { alive } 150 \\
\text { death } 128 \text { cardiac } \\
\text { death day } 10 \text { cardiac } \\
\text { alive } 15 \\
\text { alive } 24 \\
\text { alive } 30 \\
\text { alive } 168 \\
\text { alive } 12 \\
\text { alive } 36 \\
\text { alive } 18 \\
\text { alive } 31 \text { metastases } \\
\text { death } 4 \\
\text { death } 5 \\
\text { death } 6 \\
\text { alive } 96 \\
\text { death } 1 \\
\text { alive } 19 \text { metastases } \\
\text { alive } 12\end{array}$} \\
\hline & $\begin{array}{l}\text { Head } \\
\text { Head } \\
\text { Head } \\
\text { Diffuse } \\
\text { Head } \\
\text { Body } \\
\text { Head } \\
\text { Tail } \\
\text { Head } \\
\text { Head } \\
\text { Head } \\
\text { Head }\end{array}$ & $\begin{array}{l}\text { PDR II } \\
\text { PDR } \\
\text { PDR } \\
\text { PDR } \\
\text { PDR } \\
\text { CP } \\
\text { PDR } \\
\text { CP } \\
\text { PDR } \\
\text { PDR } \\
\text { PDR pp } \\
\text { PDR }\end{array}$ & $\begin{array}{l}\text { free } \\
? \\
\text { free } \\
\text { mild dysplasia } \\
? \\
\text { free } \\
\text { free } \\
\text { mild dysplasia } \\
\text { mild dysplasia } \\
\text { free } \\
\text { mild dysplasia } \\
\text { free }\end{array}$ & \\
\hline Invasive carcinoma & $\begin{array}{l}\text { Head } \\
\text { Head } \\
\text { Diffuse } \\
\text { Head } \\
\text { Head } \\
\text { Head } \\
\text { Head } \\
\text { Head } \\
\text { Diffuse }\end{array}$ & $\begin{array}{l}\text { PDR pp } \\
\text { PDR } \\
\text { CP } \\
\text { PDR } \\
\text { PDR } \\
\text { PDR } \\
\text { Palliative surgery } \\
\text { PDR } \\
\text { PDR pp }\end{array}$ & $\begin{array}{l}\text { free } \\
\text { mild dysplasia } \\
\text { mild dysplasia } \\
\text { free } \\
? \\
\text { moderate dysplasia } \\
? \\
\text { mild dysplasia } \\
\text { moderate dysplasia }\end{array}$ & \\
\hline
\end{tabular}

*Dysplasia: intraductal papillary mucinous tumour confined to the epithelium, featuring mild, moderate or severe dysplasia (adenoma, borderline tumour, carcinoma in situ). +Invasive carcinoma: papillary mucinous carcinoma with stroma (micro)invasion. $\pm S P=$ segmental pancreatectomy. $\ C P=$ caudal pancreatectomy. | $P$ PDR=pancreaticoduodenal resection. qPDR pp=pylorus preserving pancreaticoduodenal resection. one of them involving the gland diffusely. Palliative surgery was performed in one patient with an extended malignancy. Total pancreatectomy was not performed. Histopathological examination showed dysplasia in 15 patients $(62 \cdot 5 \%)$ : the grade of this dysplasia was mild (intraductal papillary adenoma) in eight, moderate (borderline tumour) in five, and severe (intraductal carcinomas or carcinoma in situ) in two. An invasive carcinoma was found in nine patients $(37.5 \%)$, including two with minimal invasion (that is, microscopic invasion of pancreatic tissue surrounding affected ducts, by a few atypical glands). Sections from resection margins were available in 20 patients: 10 were tumour free, eight showed mild dysplasia, and two moderate dysplasia. None was affected by malignancy.

Follow up of operated patients

Follow up was available on all 24 patients and averaged 47 months (1-168). The overall actuarial three year survival is $79 \%$. Survival curves are shown in Figure 10.

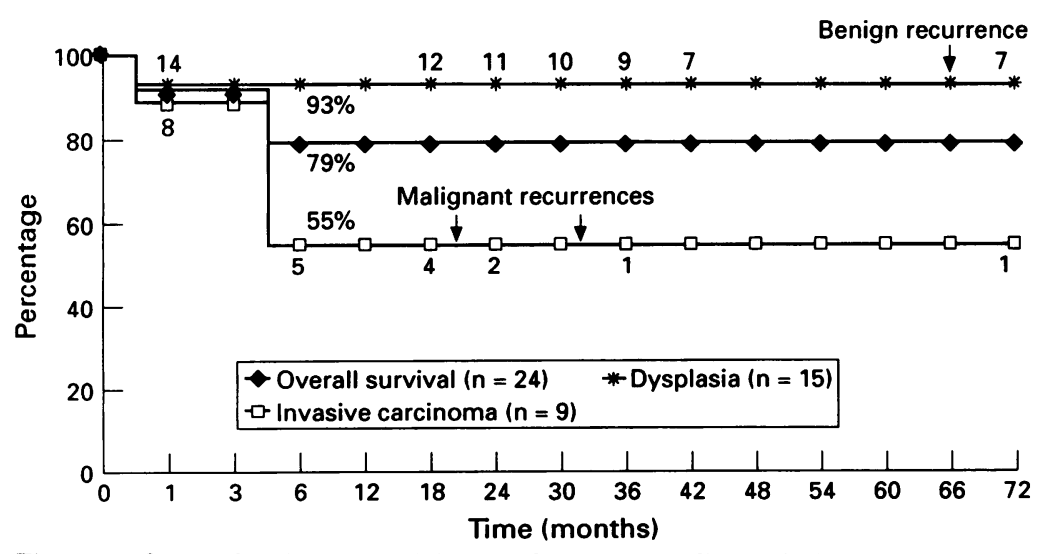

Figure 10: Operated patients actuarial survival curves, according to the histopathology.
Of the 15 patients in whom the tumour featured only dysplasia (tumour confined to the epithelium), no mortality was related to the pancreatic disease. Five of them had a surgical pancreatic margin showing residual mild dysplasia, with a postoperative follow up ranging from 12 to 150 months. Only one of them developed a benign tumoral recurrence on the remaining pancreas, 66 months after a caudal resection. This recurrence was confirmed by ERCP, showing a diffuse MPD dilatation with mucoid defects.

Four of nine patients with an invasive carcinoma died from the pancreatic malignancy within six months of surgery and two developed loco-regional or liver metastases 19 and 31 months after resection. Only three are presently alive without evidence of tumour recurrence at 12, 18, and 96 months. It must be noted that of the two patients with malignancy detected by cytology after 48 and 84 months of medical follow up, one died from generalised malignancy one month after palliative surgery, and the other was the one who developed matastases 19 months after surgery.

\section{Follow up of non-operated patients}

Follow up was completed in six patients, excluding one patient who died of myocardial infarction three days after diagnosis and one patient who refused serial ERCP. It averaged 30 months (6-60).

Of four patients presenting with relapsing pancreatitis, resolution of recurring episodes after pancreatic sphincterotomy was observed in two patients during 19 and 32 months respectively. Relapses continued in two patients: one had progressive diffuse MPD dilatation over four years, with cholestasis related to mucoid $\mathrm{CBD}$ obstruction requiring repeated ERCP for CBD and MPD mucus clearing. Pancreatitis was treated conservatively in the other patient who refused endotherapy.

Two patients had an indolent presentation. One remained asymptomatic, but had progression from cephalic to diffuse MPD dilatation. Cholestasis related to distal CBD stricture was managed by biliary stenting in another patient.

In all these patients, repeated cytologies remained negative from carcinoma.

\section{Discussion}

This study shows the distinctive features of pancreatic IPMT: the frequent presentation with relapsing pancreatitis, the characteristic pancreatographic findings, the slow growth and low recurrence rate of the tumour for as long as the tumour remains confined to the epithelium, and the poor prognosis when an invasive carcinoma has developed.

Since Ohhashi's and Takagi's original 1980 report, ${ }^{10}$ IPMT of the pancreas has attracted wide attention evidenced by a flurry of reports during the past 10 years. However, the literature remains plagued with confusion regarding 
nomenclature of these neoplasms, which are variably designated as papillomatosis, ${ }^{11}$ mucinous ductal ectasia, ${ }^{12}$ ductectatic mucinous cystadenoma, ${ }^{13}$ mucin producing carcinoma, ${ }^{8}$ and intraductal cystadenoma. ${ }^{14}$ This had led to misdiagnosis of IPMT as mucinous cystadenomas or cystadenocarcinomas. ${ }^{15}$ We therefore used the term IPMT, which encompasses all types of this particular tumour entity and reflects its main morphological features: intraductal papillary tumour growth and mucin secretion.

These tumours have mainly been reported in elderly men with an average age between 60 and 70 years. Most are located in the pancreatic head or the uncinate process though body and tail sites have been described. ${ }^{3}{ }^{16}{ }^{17}$ IPMTs are classified according to the pattern of ductal dilatation. Main duct tumours include those with diffuse (type I) or focal (type II) MPD dilatation. Branch duct tumours originate from a side branch leading to a cystic lesion (type III) or a dilated sub-branch (type IV). However overlaps between types are seen. ${ }^{18}$ IPMTs arise from the epithelial lining of the pancreatic ducts and progress along the ductal system. They may be benign, ${ }^{4}{ }^{519}$ borderline ${ }^{3}$ or malignant. Their hallmark is ductal obstruction by excessive mucus secretion and rarely by gross papillary tumour growth. ${ }^{5}{ }^{20}$ Early in the course intermittent duct plugging manifests by relapsing pancreatitis, eventually chronic obstructive pancreatitis ensues resulting in pancreatic fibrosis, acinar atrophy, and gland failure. $^{512} 21$

In a collective review of 22 cases reported in the Japanese literature, Ohhashi et al found an acute pancreatitis incidence of $50 \%{ }^{16}$ Three recent studies reported acute pancreatitis in $22 \%$ (two of nine), $29 \%$ (two of seven), and $45 \%$ (four of nine) of cases respectively. ${ }^{22-24}$ Fifty six per cent of our patients, nearly half of them older than 60 years, had suffered from recurrent episodes of pancreatitis. Though it is difficult to exclude the role of alcoholism in six patients, complete resolution of episodes after surgery in 13 patients, and in two of four patients who underwent pancreatic sphincterotomy clearly implicates IPMT in the genesis of pancreatitis. ${ }^{5}$ The long time lag between the first pancreatitis episode and correct diagnosis found in this study, mirrors the experience of others $^{41725}$ and averaged six years in a recent report. ${ }^{3}$ It attests to the slow tumour growth, the necessity for an early pancreatographic approach in pancreatitis of obscure origin, and unawareness of this entity. Indeed all but one of our patients were misdiagnosed at referral. Abdominal pain, often epigastric, without hyperamylasaemia has been attributed to IPMT in 36 to $60 \%$ of cases. ${ }^{26} 27$

An indolent course is frequently reported in IPMTs that are incidentally discovered on abdominal computed tomography or ultrasound, as in $22 \%$ of our patients and in nine of 14 patients reported by Uehara et al. ${ }^{27}$ This reflects considerable progress in pancreatic imaging. In a computed tomographic study of IPMT, high dose contrast enhanced computed tomography with $5 \mathrm{~mm}$ sections detected 19 of
20 tumours and had a higher yield than either plain or dynamic computed tomography. ${ }^{28}$ In main duct types of cystic lesion communicating with a diffusely dilated MPD and harbouring excrescent nodules or septa, or both, was seen. Clustered small $(1-2 \mathrm{~cm})$ cysts were visualised in branch duct types. Another interesting and subtle mode of presentation is a rise in amylase and lipase activities in asymptomatic patients. These abnormalities, seen in $16 \%$ of our patients and in three of nine cases in another series, ${ }^{24}$ are probably secondary to duct obstruction, and mandate further pancreatic evaluation.

Obstructive jaundice in IPMTs is seen in 14 to $50 \%$ of cases in the literature ${ }^{23-29}$ and seems more common in malignant tumours. ${ }^{26} 30$ This occurred in only two patients in our study $(6 \%)$. Involvement of the ampulla with distal CBD stricture, ${ }^{31}$ mucinous biliary obstruction, ${ }^{32}$ wirsungobiliary fistulas, ${ }^{29}$ and extrinsic CBD compression ${ }^{23}$ have been reported. Exocrine insufficiency occurs late during the course, only two of our patients had significant $(>20 \mathrm{~g} / 24 \mathrm{~h})$ steatorrhea and none of 14 evaluated patients had a function below $18 \%$ of normal. CEA and CA 19-9 values lack sensitivity and specificity in tumour detection, however increased CA 19-9 values were noted in invasive IPMT in two of four patients at diagnosis and two others during follow up.

ERCP is the gold standard for establishing the diagnosis. It provides accurate assessment of ductal abnormalities, access for intraductal biopsies, ${ }^{33}$ and cytological sampling. In a recent study of 14 patients ERCP had a sensitivity and a specificity of $91 \%$ and an overall diagnostic accuracy of $86 \% .{ }^{27} \mathrm{~A}$ patulous papilla extruding mucus though characteristic, ${ }^{23}$ is not invariably present. It was seen in $55 \%$ of our patients and in 56 to $100 \%$ of cases in other series. ${ }^{22} 29$ This study showed diffuse MPD dilatation and cysts in $71 \%$ and $42 \%$ of cases respectively. It is important to emphasise three pancreatographic features critical to the diagnosis: the absence of proximal stricture, cyst communication with the MPD, and the presence of amorphous filling defects. An MPD stricture without upstream dilatation, a previously unreported finding in benign lesions, was seen in one patient, whose lesion showed on pathology circumferential papillary growth without mucin hypersecretion. An MPD larger than 8 $\mathrm{mm}$ and a widely open papilla were reported specific for carcinoma in $81 \%$ and $91 \%$ respectively. ${ }^{27}$ In contrast, in our experience, a patulous papilla was associated with benign neoplasms in $57 \%$ of cases and neither cyst nor MPD size permitted distinction between benign and malignant tumours. Serial pancreatograms showed progressive ductal changes in four patients followed up during several years, including two in whom malignancy was subsequently detected, leading to surgery. A similar experience was reported by Obara et al who noted progression in four of nine cases and no relation between the degree of ductal dilatation and malignancy. ${ }^{22}$ IPMT can mimic chronic non-calcified pancreatitis 
both clinically and at pancreatography, making differentiation between the two entities critical. The widely open papilla, lack of proximal stricture, and amorphous defects in IPMT contrast with irregular duct contours, strictures, and corkscrewing of side branches in chronic pancreatitits. ${ }^{34} 35$

Chronic pancreatitis retention cysts should be distinguished from branch duct lesions: the first of these develop proximal to a ductal occlusion, whereas the second contain defects and are often grouped in clusters. ${ }^{12}{ }^{13}$

The deceptive yield of brushing cytology is partly related to technical factors as there are difficulties in accessing cystic lesions. However major culprits are also the pathological characteristics of these tumours - that is, the heterogeneity of the epithelial lining - leading to sampling errors. Yamada's findings lend support to this hypothesis as most malignant tumours displayed only focal cancerous areas, while benign lesions had focal atypia. ${ }^{8}$ Cytological examination of secretin stimulated pancreatic juice provides a cell washout from throughout the ductal system and has been reported in a recent study to have a sensitivity, specificity, and overall accuracy of $91 \%, 100 \%$ and $93 \%$ respectively. ${ }^{27}$

IPMT has a malignant potential evidenced by reported genetic changes and the frequency of concurrent dysplasia in malignant tumours as recently demonstrated by three dimensional computerised ductal mapping. ${ }^{18}$ K-ras mutations at codon 12 are seen in 31 to $44 \%$ of cases. ${ }^{3}$ As they occur in adenomas they are probably early events during neoplasia, ${ }^{36}$ and do not correlate with dysplasia grade as shown in a recent study that pointed to a possible relation between P53 gene mutations or P53 nuclear staining and histological differentiation, or both. ${ }^{3}$ This technique was not available for the earlier brushings in our experience and it is currently not yet possible to ascertain if it detects the malignant transformation earlier than simple cytology.

It has been suggested previously, by us and others, that IPMT could be a tumour of good prognosis after resection, due to the slow evolution and the low malignancy rate. ${ }^{5}$ The overall actuarial three year survival of the series is indeed $79 \%$. Nevertheless, $37 \cdot 5 \%$ (nine of 24 ) of the patients undergoing surgery presented an invasive carcinoma. Six of them died or developed malignant recurrence within three years of surgery. It is also noteworthy that, in at least two of our patients, malignancy developed after several years of medical follow up, suggesting that IPMT could develop from mild or moderate dysplasia to invasive carcinoma. On the other hand, no death was related to the pancreatic disease if only dysplasia was present at surgery. This suggests that the slow growing rate of benign IPMT could turn into a very aggressive tumour when an invasive carcinoma has developed. Because there are presently no reliable markers of malignant transformation of those tumours, these data should indicate that limited surgical resection should be undertaken as soon as the diagnosis of IPMT has been established and not wait for signs suggesting malignant transformation.

IPMT is sometimes considered as a disease of the entire pancreatic duct. Considering the comparatively high number of our patients operated on for a strictly intraepithelial tumour, with a pancreatic resection margin affected by mild or moderate dysplasia and at least one year follow up after surgery (five of 15 ), the $6.7 \%$ (one of 15 ) rate of benign recurrence on the remaining pancreas is surprisingly low. Reasons for this could be the slow tumour growth and the low dysplasia grade that would probably require longer follow up to uncover more recurrent disease. Nevertheless, up to now, the lack of demonstrated relation between involvement of the resection margin by dysplasia and subsequent recurrence in the remaining pancreas does not give rationale for systematic total pancreatectomy. Moreover, when pancreatographic assessment is performed early in the course of the disease, the lesion is more accurately localised, making limited surgery possible.

In summary, IPMT should be considered in the differential diagnosis of relapsing pancreatitis of obscure origin. Cross imaging studies of pancreas provide clues to the diagnosis by revealing cystic lesions along with MPD dilatation. Endoscopic pancreatography establishes the diagnosis. Given the malignant potential, early surgical resection is the mainstay treatment of IPMT.

The authors thank Dr Lourdes Tavarez, Dr Georges Ghattas, and Dr Marc Witterwulghe for providing data and Francisca Martinez Vadillo for typing this manuscript. This work was presented in part at Digestive Disease Week in San Diego, May presen
1995.

1 Suyama $\mathrm{M}$, Ariyama J, Ogawa $\mathrm{K}$. Clinical diagnosis of mucin producing pancreatic carcinoma. $\mathcal{f}$ Biliary Tract Pancreas 1986; 7: 739-45.

2 Klöppel G. Pancreatic non endocrine tumours. In: Klöppel H, Heitz $\mathrm{PH}$, eds. Pancreatic pathology. Edinburgh: Churchill Livingstone, 1984: 79-113.

3 Sessa F, Solcia E, Capella C, Bonato M, Scarpa A,Zamboni G, et al. Intraductal papillary-mucinous tumors represent a distinct group of pancreatic neoplasms: an investigation of tumor cell differentiation and K-ras, p53 and c-erbB-2 abnormalities in 26 patients. Virchows Arch 1994; 425: abnormalit

4 Morohoshi T, Kanda M, Asanuma K, Klöppel G. Intraductal papillary neoplasms of the pancreas. A clinicopathologic study of six patients. Cancer 1989; 64: 1329-35.

5 Rickaert F, Cremer M, Devière J, Tavares L, Lambilliotte JP, Schröder $\mathrm{S}$, et al. Intraductal mucin-hypersecreting neoplasms of the pancreas. A clinicopathologic study of eight patients. Gastroenterology 1991; 101: 512-9.

6 Warshaw AL, Berry J, Gang DL. Villous adenoma of the

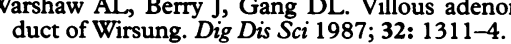

7 Place S, Louvel A, Farhi JP, Chapuis S. Adénocarcinome papillaire du canal de Wirsung. Gastroenterol Clin Biol 1985; 9: 361-4.

8 Yamada M, Kozuka S, Yamao K, Nakazawa S, Naitoh Y, Tsukamoto Y. Mucin-producing tumor of the pancreas. Cancer 1991; 68: 159-68.

9 Devière J, Gulbis B, Delhaye M, Quenon M, Cremer M. A study of the relationship between the canalar morphology and the exocrine function of the pancreas. A new method of linear estimation of the pancreatic function. Acta Endoscopica 1985; 15: 403-14.

10 Ohhashi $\mathrm{K}$, Takagi K. ERCP and imaging diagnosis of pancreatic cancer. Gastroenterol Endosc 1980; 77: 1493-5.

11 Haban G. Papillomatose und carcinom des Gangsystems der Bauchspeicheldrüse. Virchows Arch 1936; 297: 207-20.

12 Bastid C, Bernard JP, Sarles H, Payan MJ, Sahel J. astid C, Bernard JP, Sarles H, Payan MJ, Sahel J. Mucinous ductal ectasia of the pancreas: a premalignant 1991; 6: 15-22.

13 Itai Y, Ohhashi K, Nagai H, Murakami Y, Kokubo T, Makita K, et al. 'Ductectatic' mucinous cystadenoma and cystadenocarcinoma of the pancreas. Radiology 1986; 161: $697-700$. 
14 Köhler B, Köhler G, Riemann NJ. Pancreatoscopic diagnosis of intraductal cystadenoma of the pancreas. Dig Dis Sci 1990; 35: 382-4.

15 Katoh H, Rossi RL, Braash JW, Munson JL, Shimozawa E, Tanabe T. Cystadenoma and cystadenocarcinoma of the pancreas. Hepatogastroenterology 1989; 36: 424-30.

16 OhhashiK, MurakamiY,IkegoshiT, TagakiK, Yanagisawa A Kato Y. Mucin-producing pancreatic cancer. Stomach Kato Y. Mucin-producing
Intestine 1986; 21: 755-66.

17 Nakazawa S. Mucin producing tumor of the pancreas. Tokyo: Igaku Shoin, 1989

18 Furukawa T, Takahashi T, Kobari M, Matsuno S. The mucin hypersecreting tumor of the pancreas. Development and extension visualized by three-dimensiona computerized mapping. Cancer 1992; 70: 1505-13.

19 Obara T, Saitoh Y, Maguchi H, Ura H, Yokota KI, Okamura K, et al. Papillary adenoma of the pancreas with excessive mucin secretion. Pancreas 1992; 7: 114-7.

20 Warshaw A, Compton C, Lewandrowski K, Cardenosa G, Mueller P. Cystic tumors of the pancreas. New clinical, radiological and pathologic observations in 67 patients. Ann Surg 1990; 212: 432-45.

21 Lowes JR, Rode J, Lees WR, Russell RCG, Cotton PB. Lowes JR, Rode J, Lees WR, Russell RCG, Cotton PB. Obstructive pancreatitis: unusual cause

22 Obara T, Maguchi H, Saitoh Y, Akinori I, Arisato S, Ashida T, et al. Mucin-producing tumor of the pancreas: natura history and serial pancreatogram changes. $A m$ Gastroenterol 1993; 88: 564-9.

23 Yamaguchi K, Tanka M. Mucin-hypersecreting tumor of the pancreas with mucin extrusion through an enlarged papilla. Am 7 Gastroenterol 1991; 86: 835-9

24 Obara T, Maguchi H, Saitoh Y, Ura H, Koike Y, Kitazawa S, et al. Mucin producing tumor of the pancreas: a unique clinical entity. Am $f$ Gastroenterol 1991; 86: 1619-25.

25 Ohta T, Nagakawa T, Akiyama T, Fukushima W, Keno K, Miyazaki I, et al. The 'duct-ectatic' variant of mucinous cystic neoplasm of the pancreas: clinical and radiologic cystic neoplasm of the pancreas: clinical and radiologic $300-4$.
26 Itai Y, Kokubo T, Atomi Y, Kuroda A, Haraguchi Y, Terano A. Mucin-hypersecreting carcinoma of the pancreas. Radiolgy 1987; 165: 51-5.

27 Uehara H, Nakaizumi A, Ieshi H, Tatsuka M, Kitamara T, Okuda S, et al. Cytologic examination of pancreatic juice for differential diagnosis of benign and malignant mucin producing tumors of the pancreas. Cancer 1994; 74: producin

28 Itoh S, Ishiguchi $T$, Ishigaki $T$, Sakuma S, Maruyama $K$, Senda K. Mucin-producing pancreatic tumor CT findings and histopathological correlation. Radiology 1992; 183: 81-6.

29 Raijman I, Kortan P, Walden G, Kandel N, Marcon E, Haber GB. Mucinous ductal ectasia. Cholangiopancreatographic end endoscopic findings. Endoscopy 1994 26: 303-7.

30 Milchgrub S, Campuzano M, Casillos J, Albores-Saavedra J. Intraductal carcinoma of the pancreas. Cancer 1992; 69: 651-6.

31 Smith RC, Kneale K, Goulston K. In situ carcinoma of the pancreas. Aust NZ ₹ Surg 1986; 56: 369-73.

32 Ito Y, Blackstone MO, Frank PH, Skinner DB. Mucinous biliary obstruction associated with a cystic adenobiliary obstruction associated with a cystic adenocarcinoma

33 Obara T, Maguchi H, Saitoh Y, Sohma M, Tsuji K, Koike Y, et al. Intraductal papillary neoplasms of the pancreas: diagnosis by endoscopic pancreatic biopsy. Endoscopy 1993; 25: 290-3.

34 Jones SN, Lees WR, Frost RA. Diagnosis and grading of chronic pancreatis by morphologic criteria derived by ultrasound and pancreatography. Clin Radiol 1988; 39: 43-8.

35 Axon ATR, Classen M, Cotton PB, Cremer M, Freeny PC Lees WR. Pancreatography in chronic pancreatitis. Lees WR. Pancreatography in chronic panc

36 Tada $M$, Omata $M$, Ohoto $M$. Ras gene mutations in intraductal papillary neoplasms of the pancreas. Cancer 1991; 67: 634-7. 